Article

\title{
Cooling Enhancement and Stress Reduction Optimization of Disk-Shaped Electronic Components Using Nanofluids
}

\author{
Reza Dadsetani ${ }^{1}$, Ghanbar Ali Sheikhzadeh ${ }^{1}$, Mohammad Reza Safaei ${ }^{2, * \mathbb{D}}$, Arturo S. Leon ${ }^{2}$ \\ and Marjan Goodarzi ${ }^{3}$ (D) \\ 1 Heat \& Fluids Department, University of Kashan, Kashan 87317-51167, Iran; R.dadsetani@me.iut.ac.ir (R.D.); \\ sheikhz@kashanu.ac.ir (G.A.S.) \\ 2 Department of Civil and Environmental Engineering, Florida International University, \\ Miami, FL 33174, USA; arleon@fiu.edu \\ 3 Sustainable Management of Natural Resources and Environment Research Group, Faculty of Environment \\ and Labour Safety, Ton Duc Thang University, Ho Chi Minh City 700000, Vietnam; \\ marjan.goodarzi@tdtu.edu.vn \\ * Correspondence: msafaei@fiu.edu; Tel.: +1-502-657-9981
}

Received: 18 March 2020; Accepted: 1 May 2020; Published: 3 June 2020

\begin{abstract}
Mechanical strength and thermal properties may limit the usage of an electronic component in the high-tech industry. This paper investigated the influence of using $\mathrm{CuO}$ nanoparticles in a radial configuration microchannel of a disk from the mechanical and thermal points of view. In this regard, a disk under thermal and mechanical loading had been considered. The cooling setup consisted of a radial configuration microchannel with a constant fluid volume. Water was used as the base fluid and $\mathrm{CuO}$ particles were used as the coolant fluid. The results showed that the use of $\mathrm{CuO}$ nanoparticles would reduce the maximum disk temperature, the maximum thermal stress, and the maximum stress, as well as the maximum deformation on the body. The increasing number of channels would increase the maximum stress in the object as well. Another remarkable point was that increasing the nanoparticles did not necessarily lead to a more uniform heat distribution in the disk.
\end{abstract}

Keywords: mechanical enhancement; symmetrical radial microchannel configuration; nanofluid; electronic disk-shaped components

\section{Introduction}

One of the crucial parameters in technology advancement is the efficiency of electronic components. One of the main limitations affecting the performance of electronic components is transferring the heat from them. Wide ranges of studies have been carried out on this subject, and different approaches have been proposed [1-14]. One of these methods is using microchannels containing cooling fluids. This method was first introduced in 1981 by Tuckerman and Peace [15]. They showed that by using microchannels, heat transfer could be increased up to 40 times higher, and introduced microchannel-cooling as a high-efficiency small-sized method. After demonstrating the high efficiency of cooling with microchannels, the researchers studied the different applications, design aspects, and optimization of this method. The constructal theory is one of the optimization theories introduced by Adrian Bejan [16] that could be used to improve the heat sinks microchannel. This theory aims to enhance the shape and configuration of a microchannel. One of the introduced microchannels configurations by the constructal theory in a disk is known as the radial configuration. In this study, this kind of microchannel configuration in the disk was pursued. Another solution to improve the microchannel cooling efficiency is to enhance the physical properties of the microchannel fluid. 
Generally, conventional fluids have low thermal conductivity. To overcome this problem, S.U.S. Chol [17] achieved a higher thermal conductivity in working fluid by adding nanoparticles of metals in the working fluid. Dispersing the nanomaterial in the base fluid has made nanofluid with higher conduction, which can transfer more heat. In the recent three decades, the use of various nanoparticles and their effectiveness on heat transfer has been studied and analyzed by various researchers [12,18-32].

Another challenge in the design of electronic components in advanced technologies, such as electronic packages and structures of future air vehicles industries, is the weight and strength restrictions of the element [33]. One of the ways of increasing the strength of the electronic component is to add materials with a higher strength coefficient, but the downside of this method is the increase in the element weight. Therefore, the challenge is increasing the strength of the element without increasing its weight. In these technologies, because of the high rate of heat transfer, the thermal stresses play a crucial role in the component strength.

Gosselin et al. [34] optimized the combination of the heat transfer and strength of the materials analytically. The beam profile loaded has been optimized for bending by enhancing the lifetime in the existence of sudden heating. Besides, the cross-section of the beam and the position of the steel bars have been investigated. Cetkin et al. [33,35] examined the effect of vascular design on the mechanical and thermal stress in the radial and dendritic microchannel network. They found that the cooling capability of the vascular design reduced by decreasing the thermal stress.

So far, the use of nanofluids in the radial configuration has not been studied extensively. Also, the lack of a proper study to analyze the stresses of a cooled piece by nanofluid is felt. Therefore, in this research, an electronic element that was under thermal flux and mechanical loading was considered. In order to cool the disk, some microchannels were embedded inside it. In all examined cases, the volume of embedded channels was assumed constant. Water/CuO nanofluid was used at $4 \%$ and $2 \%$ volume fraction. The effect of using nanofluid on the maximum temperature, the von Mises stress, thermal stress, and total deformation had been investigated.

\section{Model}

To model electronic cooling equipment, such as processors, a disk with a radius of $\mathrm{R}$, the diameter of $\mathrm{D}$, and the height of $\mathrm{H}=0.1 \mathrm{D}$ were considered. The ratio of the cooling zone to the volume of the disk was assumed to be $5 \%$ in all cases $[15,16,31,32]$. The radial duct diameter varied with the duct numbers. The outer surface of the disk had been considered stationary, whereas the top and bottom surfaces were considered moving. The disk center was considered as the entrance of the cooling fluid. After uniform heat exchange with the bottom disk, it exited the system through the edge of the disk. Figure 1 shows the schematics of the studied cooling system. In the following microchannel network, the microchannel was extended to all cooling zone in volume (convection method).

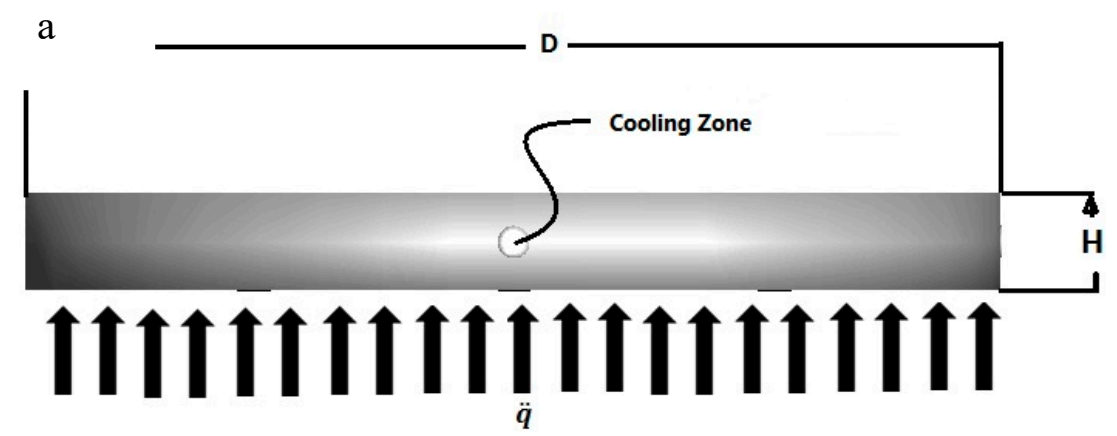

Figure 1. Cont. 


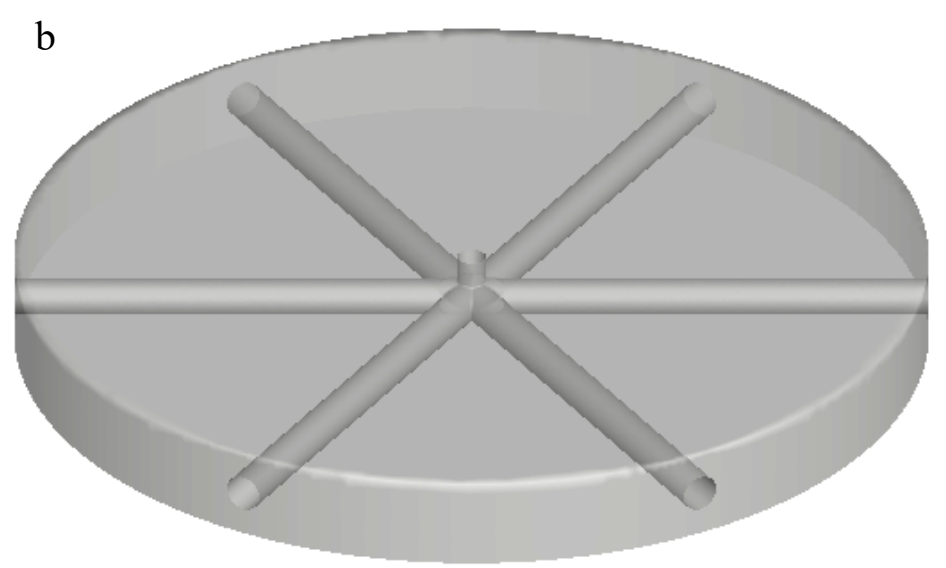

Figure 1. (a) Side view of the modeled disk. (b) Front view of modeled disk.

Because of the frequent utilization of silicon as the most popular solid in the electronics industry and water as base fluid, the properties of these two materials were considered and listed in Table 1.

Table 1. Properties of considered solid and fluid.

\begin{tabular}{ccc}
\hline Property & Silicon & Water \\
\hline Density, $\rho\left(\mathrm{kg} / \mathrm{m}^{3}\right)$ & 2330 & 997 \\
Thermal conductivity, $k(\mathrm{~W} / \mathrm{m} \mathrm{K})$ & 125 & 0.6069 \\
Specific heat capacity, $C_{p}(\mathrm{~J} / \mathrm{kg} \mathrm{K})$ & 700 & 4187.7 \\
Dynamic viscosity, $\mu$ (Pa.s) & - & 0.00089 \\
\hline
\end{tabular}

\subsection{The Governing Equations}

Heat is transferred through the solid and fluid regions by conduction and convection, respectively. The radiative heat transfer and gravity forces were neglected. In this study, the hydraulic diameter of the microchannel was chosen greater than $10 \mu \mathrm{m}$, so the fluid could be considered as a continuum. Therefore, Navier-Stokes and Fourier equations could be applied. Moreover, the energy and Navier-Stokes equations were coupled with the equation of solid heat transfer. The conductivity was considered to be uniform and isotropic. Due to the significant value of the conductivity coefficient, lasting time was smaller than a second to attain a steady-state temperature inside the microchannel. Nanofluid was assumed to be incompressible with Newtonian behavior and had a laminar flow. Nanoparticles were assumed to be spherical and had the same diameter. The base fluid and nanoparticles moved with the same velocity, and they were at the same thermal conditions. In other words, the nanofluid mixture was homogeneous. According to the mentioned assumptions, the mass conservation and momentum equations for the nanofluid were as follows:

$$
\begin{gathered}
\frac{\partial u}{\partial x}+\frac{\partial v}{\partial y}+\frac{\partial w}{\partial z}=0 \\
u \frac{\partial u}{\partial x}+v \frac{\partial u}{\partial y}+w \frac{\partial u}{\partial z}=-\frac{1}{\rho_{n f}} \frac{\partial p}{\partial x}+\frac{\mu_{e f f}}{\rho_{n f}} \nabla^{2} u \\
u \frac{\partial v}{\partial x}+v \frac{\partial v}{\partial y}+w \frac{\partial v}{\partial z}=-\frac{1}{\rho_{n f}} \frac{\partial p}{\partial y}+\frac{\mu_{e f f}}{\rho_{n f}} \nabla^{2} v \\
u \frac{\partial w}{\partial x}+v \frac{\partial w}{\partial y}+w \frac{\partial w}{\partial z}=-\frac{1}{\rho_{n f}} \frac{\partial p}{\partial z}+\frac{\mu_{e f f}}{\rho_{n f}} \nabla^{2} w
\end{gathered}
$$

Here, $\nabla^{2}=\frac{\partial^{2}}{\partial x^{2}}+\frac{\partial^{2}}{\partial y^{2}}+\frac{\partial^{2}}{\partial z^{2}}$. 
The energy equations for fluid was

$$
\rho_{n f} C_{p, n f}(U . \nabla T)=K_{n f} \nabla^{2} T
$$

Effective viscosity and nanofluid density were defined as follows:

$$
\begin{gathered}
\rho_{n f}=\xi \rho_{n p}+(1-\xi) \rho_{b f} \\
\mu_{e f f}=\mu_{b f} /(1-\xi)^{2.5} .
\end{gathered}
$$

The proposed formula by Chol et al. [17], which considers the diameters well as the Brownian motion of the nanoparticles, was used to compute the effective conductivity of the nanofluid:

$$
\frac{k_{e f f}}{k_{b f}}=1+64.7 \times \xi^{0.7460}\left(\frac{d_{b f}}{d_{n p}}\right)^{0.3690}\left(\frac{k_{n f}}{k_{b f}}\right) \times\left(\frac{\mu}{\rho_{b f} \alpha_{b f}}\right)^{0.9955}\left(\frac{\rho_{b f} B_{c} T}{3 \pi \mu^{2} L_{B F}}\right)^{1.231}
$$

where "LBF" is the mean free path of the base fluid, and " $B_{c}$ " the Boltzmann constant $\left(1.3807 \times 10^{-23} \mathrm{~J} / \mathrm{K}\right)$, and $\mu$ was calculated as

$$
\mu=A \times 10^{\frac{B}{T-C}}, C=140(K), B=247(K), A=2.414 \times 10^{-5}(\text { Pa.s })
$$

The distribution of temperature into the solid zones was obtained by solving the energy equation:

$$
K_{s} \nabla^{2} T_{s}=0 \Rightarrow \nabla^{2} T_{s}=0
$$

The thermal boundary conditions for the upside surface was:

$$
K_{s} \frac{\partial T}{\partial y}=-q^{\prime \prime}
$$

Sidewalls were adiabatic. In the solid-solid and solid-liquid interfaces, and due to the continuity of temperature and heat flux and the fluid in the joint, we had:

$$
K_{s} \frac{\partial T_{s l}}{\partial n}\left|\Omega=K_{n f} \frac{\partial T_{f}}{\partial n}\right| \Omega \text { and } T_{s}\left|\Omega=T_{n f}\right| \Omega
$$

where $\Omega$ is a perpendicular vector to the solid-solid and solid-liquid interfaces. Based on previous findings, solid disks assumed isotropic, with elastic deformations. According to this hypothesis, Hoke law and momentum equations could be expressed as [35]:

$$
\begin{gathered}
\frac{\partial \sigma_{x x}}{\partial x}+\frac{\partial \tau_{y x}}{\partial y}+\frac{\partial \tau_{z x}}{\partial z}=0 \\
\frac{\partial \sigma_{y y}}{\partial y}+\frac{\partial \tau_{x y}}{\partial x}+\frac{\partial \tau_{z x}}{\partial z}=0 \\
\frac{\partial \sigma_{z z}}{\partial z}+\frac{\partial \tau_{y z}}{\partial y}+\frac{\partial \tau_{x z}}{\partial x}=0 \\
{\left[\begin{array}{l}
\sigma_{x x} \\
\sigma_{y y} \\
\sigma_{z z} \\
\tau_{y z} \\
\tau_{z x} \\
\tau_{x y}
\end{array}\right]=\frac{E}{(1+\gamma)(1-2 \gamma)}\left[\begin{array}{cccccc}
1-\gamma & \gamma & \gamma & 0 & 0 & 0 \\
\gamma & 1-\gamma & \gamma & 0 & 0 & 0 \\
\gamma & \gamma & 1-\gamma & 0 & 0 & 0 \\
0 & 0 & 0 & \frac{1-2 \gamma}{2} & 0 & 0 \\
0 & 0 & 0 & 0 & \frac{1-2 \gamma}{2} & 0 \\
0 & 0 & 0 & 0 & 0 & \frac{1-2 \gamma}{2}
\end{array}\right]\left[\begin{array}{c}
\varepsilon_{x x} \\
\varepsilon_{x y} \\
\varepsilon_{x z} \\
\varphi_{y z} \\
\varphi_{x z} \\
\varphi_{x y}
\end{array}\right]}
\end{gathered}
$$


The effect of the thermal stress on the disk was considered by the relationship between temperature and solid equations, which could be written as follows:

$$
\left[\begin{array}{c}
\varepsilon_{x x} \\
\varepsilon_{y y} \\
\varepsilon_{z z} \\
\phi_{y z} \\
\phi_{z x} \\
\phi_{x y}
\end{array}\right]=\left[\begin{array}{c}
\varepsilon_{m, x x} \\
\varepsilon_{m, y y} \\
\varepsilon_{m, z z} \\
\phi_{m, y z} \\
\phi_{m, z x} \\
\phi_{m, x y}
\end{array}\right]-\left(T-T_{r e f}\right)\left[\begin{array}{c}
\alpha \\
\alpha \\
\alpha \\
0 \\
0 \\
0
\end{array}\right]
$$

Displacement and strain relations could be represented as below:

$$
\begin{gathered}
\varepsilon_{m, x x}=\frac{\partial r_{x}}{\partial x} \\
\varepsilon_{m, y y}=\frac{\partial r_{y}}{\partial y} \\
\varepsilon_{m, z z}=\frac{\partial r_{z}}{\partial z} \\
\varphi_{m, x y}=\frac{\partial r_{x}}{\partial y}+\frac{\partial r_{y}}{\partial x} \\
\varphi_{m, y z}=\frac{\partial r_{z}}{\partial y}+\frac{\partial r_{y}}{\partial z} \\
\varphi_{m, z x}=\frac{\partial r_{z}}{\partial x}+\frac{\partial r_{x}}{\partial z}
\end{gathered}
$$

Total deformation could be calculated as:

$$
\begin{gathered}
D e=\sqrt{r_{x}^{2}+r_{y}^{2}+r_{z}^{2}} \\
D e^{*}=\frac{D e}{2 R}
\end{gathered}
$$

Dimensionless variables could be defined as follows:

$$
\begin{gathered}
T^{*}=\frac{T-T_{\text {in }}}{\frac{q^{\prime \prime} R}{K_{s}}} \\
P^{*}=\frac{\left(P_{\text {in }}-P_{\text {out }}\right) R^{2}}{\mu \alpha_{f}}
\end{gathered}
$$

The value of $P^{*}$ demonstrates the difference in overall pressure between the inlet and outlet of the duct. $P^{*}$ values of order $10^{7}$ and $10^{8}$ had been used, which showed Reynolds numbers smaller than 2000 in each channel. Also, we assumed $\gamma=0.33$ and $E^{*}=2 \times 10^{6}$. The thermal expansion coefficient was considered equal to $10^{-4}$.

\subsection{Grid-Independence Study and Validation}

In order to mesh the geometry, an irregular grid was used. The grids were refined near the cooling zone and the interface. The results were analyzed at various mesh numbers to examine maximum velocity, the peak temperature ( $T_{\max }$, Table 2$)$, and the maximum stress (Table 3 ) to obtain less than $1 \%$ variation. The traditional package of simulation ANSYS CFX and ANSYS STATIC STRUCTURAL software was used for this purpose. For the velocity-pressure coupling, a SIMPLE algorithm was used. Convergence had been acquired with the error magnitudes less than $10^{-5}$. The geometry and other conditions in the current study were considered similar to Cetkin et al. [35]. As could be seen in Figure 2, there was an excellent agreement for thermal stress, mechanical load, and a combination of both loads between present modeling and findings of Cetkin et al. [35]. 
Table 2. Results in $T_{\max }$ per number of elements.

\begin{tabular}{cc}
\hline Number of Elements & $\boldsymbol{T}_{\max }(\mathbf{K})$ \\
\hline 879,314 & 435.9 \\
$2,169,346$ & 429.8 \\
$3,256,892$ & 425.6 \\
$5,142,765$ & 424.3 \\
\hline
\end{tabular}

Table 3. Results in $\sigma_{\max }$ per number of elements.

\begin{tabular}{cc}
\hline Number of Elements & $\sigma_{\max }($ Mpa) Variation \\
\hline 879,314 & 3.4281 \\
$2,169,346$ & 3.3452 \\
$3,256,892$ & 3.1252 \\
$5,142,765$ & 3.1118 \\
\hline
\end{tabular}

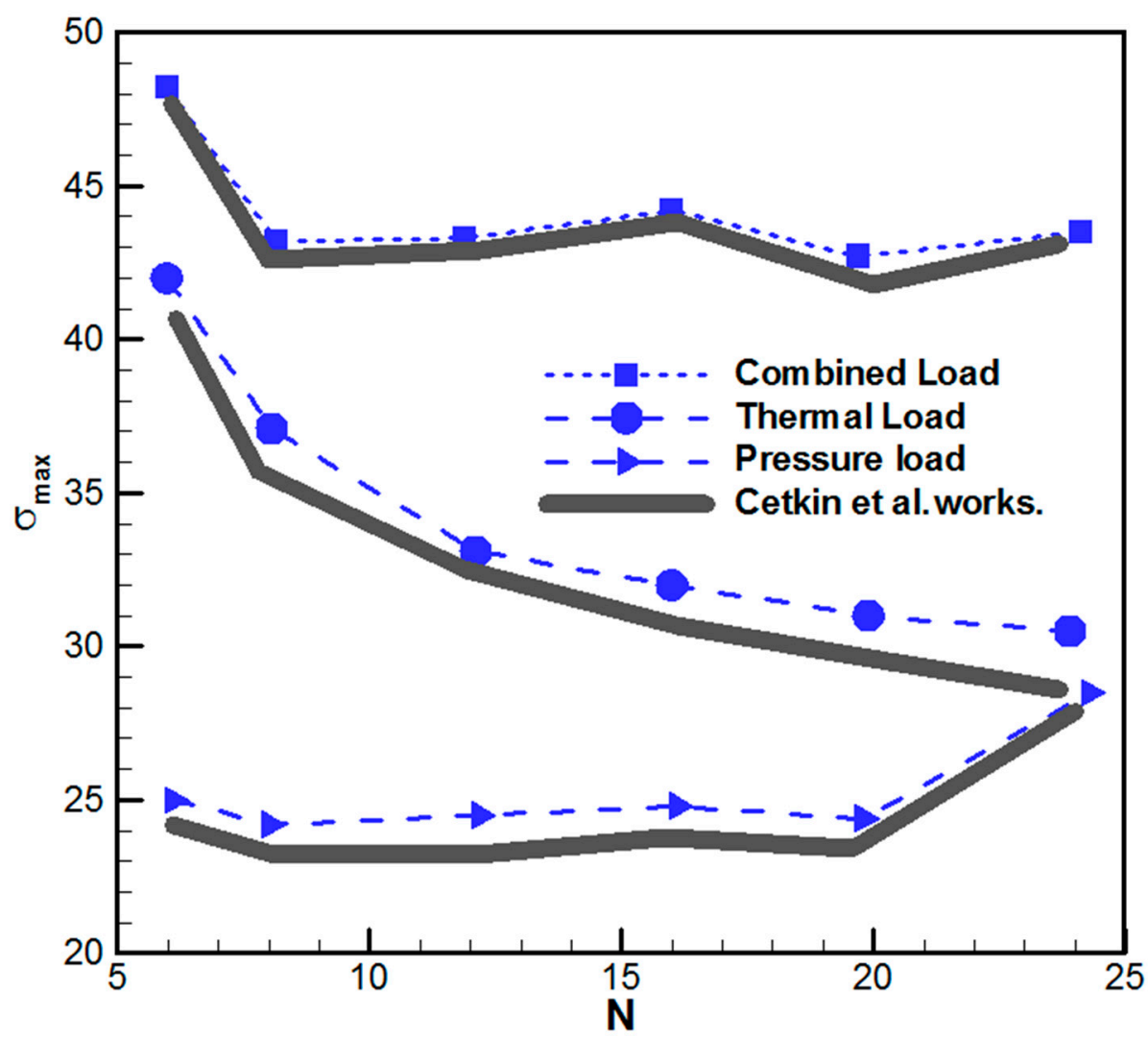

Figure 2. A comparison of the dimensionless maximum Von Mises stress, based on several microchannels, compared to Cetkin et al. [35] work.

\section{Result and Discussion}

In this work, the vascular structures of a microchannel containing water and $\mathrm{CuO}$ - water nanofluid in a radial configuration were investigated. To achieve this goal, we examined the mechanical load, thermal load, and the cooling zone volume for all cases. Based on Equations (3) to (6), it was observed that the nanoparticle volume fraction had a significant effect on the overall thermal conductivity of the nanofluid, meaning that it was a much better heat conductor compared to the initial working fluid. Nevertheless, due to the increasing motions of the nanoparticles with temperature, which was a result of the Brownian effect, the thermal conductivity of the nanofluid depended mainly on the temperature. Furthermore, increasing the temperature caused the viscosity of the fluid to decrease, which facilitated 
the Brownian effect. The following sections discuss the effects of nanoparticle volume fraction on the thermal and mechanical behavior of the disk.

\subsection{Thermal}

The uniform maximum temperature and uniform temperature distribution are critical design parameters due to generating the best heat configuration. Based on the constructal theory, the ideal condition can be obtained when the temperature distribution becomes uniform over the component. On the other hand, the component's best temperature is achieved when it reaches $T_{\max }$ throughout the disk. The latter means that the best design is obtained when the average temperature is near $T_{\max }$.

Figure $3 \mathrm{a}, \mathrm{b}$ represents the maximum dimensionless temperature variations by several ducts for different $\xi=0 \%, 2 \%$, and $4 \%$. Figure $3 \mathrm{a}, \mathrm{b}$ indicates how the peak temperature changed, relative to the volume fraction of nanoparticles and the number of cooling channels, at $P^{*}$ max $=10^{7}$ and $P^{*}$ max $=10^{8}$, respectively. For $P^{*}{ }_{\text {max }}=10^{8}$, the peak temperature boosted as $\mathrm{N}$ increased when the volume fraction was $0 \%, 2 \%$, and $4 \%$. However, for $P^{*}{ }_{\max }=10^{7}$, the peak temperature was obtained at $\mathrm{N}=14$. In both studied $P^{*}{ }_{\text {max }}$, the peak temperature decreased as the volume fraction of nanoparticles increased. For the same $\mathrm{N}$, the difference between maximum temperatures was larger for the range of $\xi$ between $0 \%$ and $2 \%$ compared to that between $2 \%$ and $4 \%$. For the studied cases, by increasing the volume fraction of nanoparticle from $0 \%$ to $2 \%$, the peak temperature decreased from $14.5 \%$ to $30 \%$ (for $P^{*}{ }_{\max }=10^{7}$ ) and $19.6 \%$ to $28.9 \%$ (for $P^{*}{ }_{\max }=10^{8}$ ). Moreover, by nanoparticle volume fraction augmentation from $0 \%$ to $4 \%$, the peak temperature decreased from $27.3 \%$ to $44 \%$ (for $P^{*}{ }_{\max }=10^{7}$ ) and from $33.2 \%$ to $44.7 \%$ (for $P^{*}$ max $=10^{8}$ ).

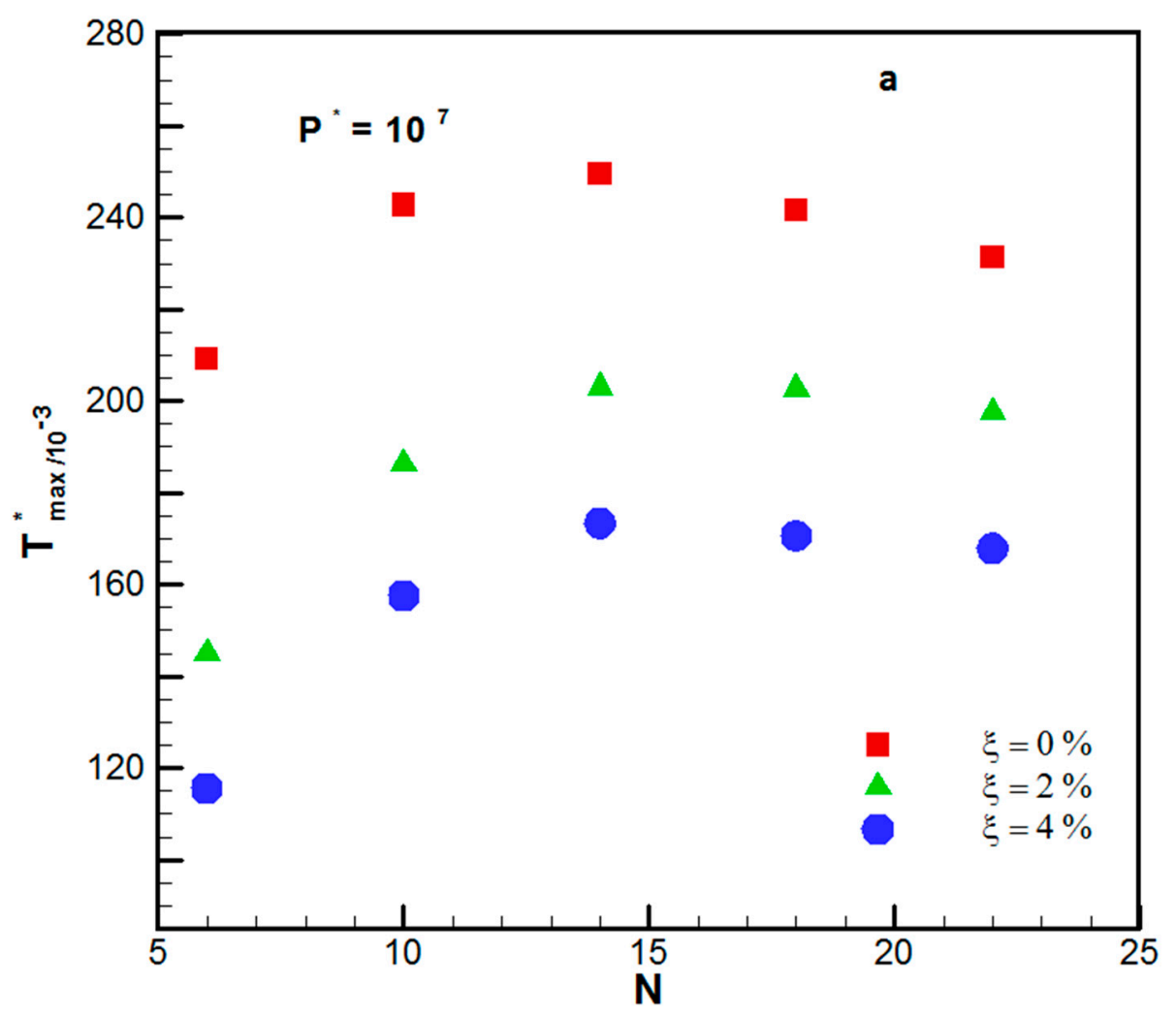

Figure 3. Cont. 


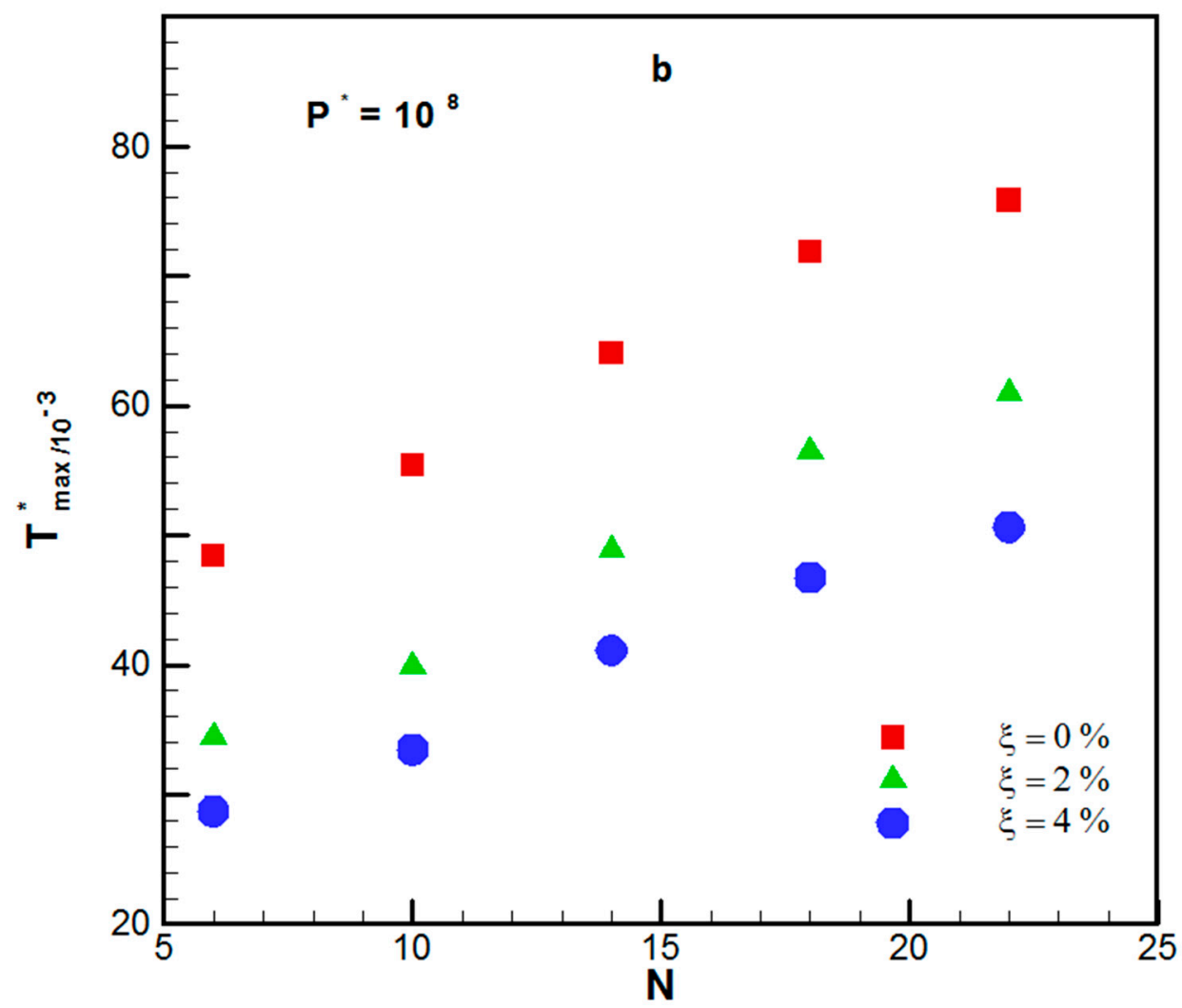

Figure 3. (a) $T^{*}$ max versus $N$ for the different volume fraction of nanoparticles under $P^{*}=10^{7}$. (b) $T^{*} \max$ versus $\mathrm{N}$ for the different volume fraction of nanoparticles $P^{*}=10^{8}$.

Table 4 shows the variation of the maximum temperature for various nanoparticles volume fractions and multiple numbers of microchannels. As shown in Table $4, \Delta T_{\max }^{*}$ is decreased when the number of ducts is increased.

Table 4. Percentage change in $\Delta T_{\max }^{*}$ by changing the number of ducts for $\xi=2 \%$ and $4 \%$.

\begin{tabular}{|c|c|c|c|c|}
\hline \multirow{2}{*}{$\begin{array}{c}\text { Variation } \Delta T_{\max }^{*} \\
\begin{array}{c}\text { volume fraction of } \\
\text { nanofluids }\end{array}\end{array}$} & \multicolumn{2}{|c|}{ 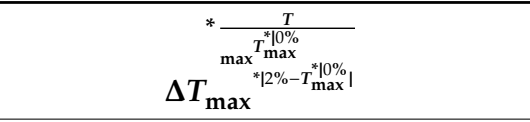 } & \multicolumn{2}{|c|}{ 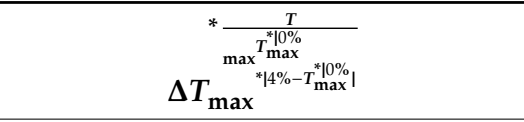 } \\
\hline & \multicolumn{2}{|c|}{$\zeta=0 \%$ to $2 \%$} & \multicolumn{2}{|c|}{$\zeta=0 \%$ to $4 \%$} \\
\hline $\mathbf{N}$ & $P_{\max }^{*}=10^{7}$ & $P_{\max }^{*}=10^{8}$ & $P_{\max }^{*}=10^{7}$ & $P_{\max }^{*}=10^{8}$ \\
\hline 6 & $\Delta T_{\max }^{*}-30.74 \%$ & $\Delta T_{\max }^{*}-28.99 \%$ & $\Delta T_{\max }^{*}-44.74 \%$ & $\Delta T_{\max }^{*}-40.71 \%$ \\
\hline 8 & $\Delta T_{\max }^{*}-23.27 \%$ & $\Delta T_{\max }^{*}-28.02 \%$ & $\Delta T_{\max }^{*}-35.05 \%$ & $\Delta T_{\max }^{*}-39.61 \%$ \\
\hline 14 & $\Delta T_{\max }^{*}-18.66 \%$ & $\Delta T_{\max }^{*}-23.77 \%$ & $\Delta T_{\max }^{*}-30.53 \%$ & $\Delta T_{\max }^{*}-35.82 \%$ \\
\hline 18 & $\Delta T_{\max }^{*}-16.14 \%$ & $\Delta T_{\max }^{*}-21.52 \%$ & $\Delta T_{\max }^{*}-29.38 \%$ & $\Delta T_{\max }^{*}-34.99 \%$ \\
\hline 22 & $\Delta T_{\max }^{*}-14.54 \%$ & $\Delta T_{\max }^{*}-19.67 \%$ & $\Delta T_{\max }^{*}-27.38 \%$ & $\Delta T_{\max }^{*}-33.23 \%$ \\
\hline
\end{tabular}

A uniform temperature distribution, such as the maximum temperature of a segment, is important in the cooling of electronic parts. According to the constructal theory, the arrangement of microchannels is optimal once the whole segment would be at one unique temperature. The ideal condition is that the peak temperature and the segment temperature would be the same. Figure $4 a, b$ indicates the uniformity of temperature based on the $\frac{T_{\text {ave }}}{T_{\max }}$. As observed in these figures, the best uniformity is obtained when using 10 ducts. According to Figure $4 \mathrm{a}$, for $P^{*}=10^{7}$ and at duct numbers less than 10 , the most uniformity of temperature was ascribed to the distilled water, in comparison with other concentrations of nanoparticles. The same results could be expressed for duct numbers less than ten and $P^{*}=10^{8}$. For duct numbers less than ten, the uniformity of temperature related to the concentration of $4 \%$ was 
less than $2 \%$ and $0 \%$. However, for duct numbers greater than 10 , the uniformity of concentration $4 \%$ was greater than the two other volume fractions.

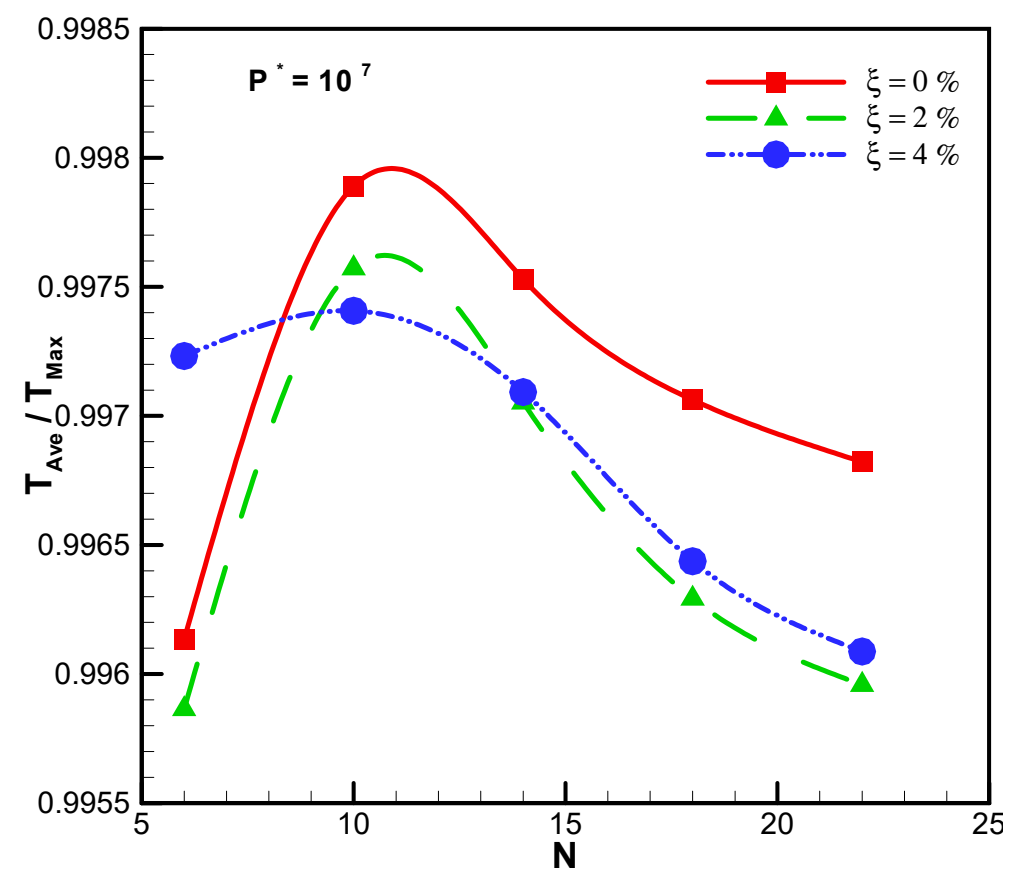

(a)

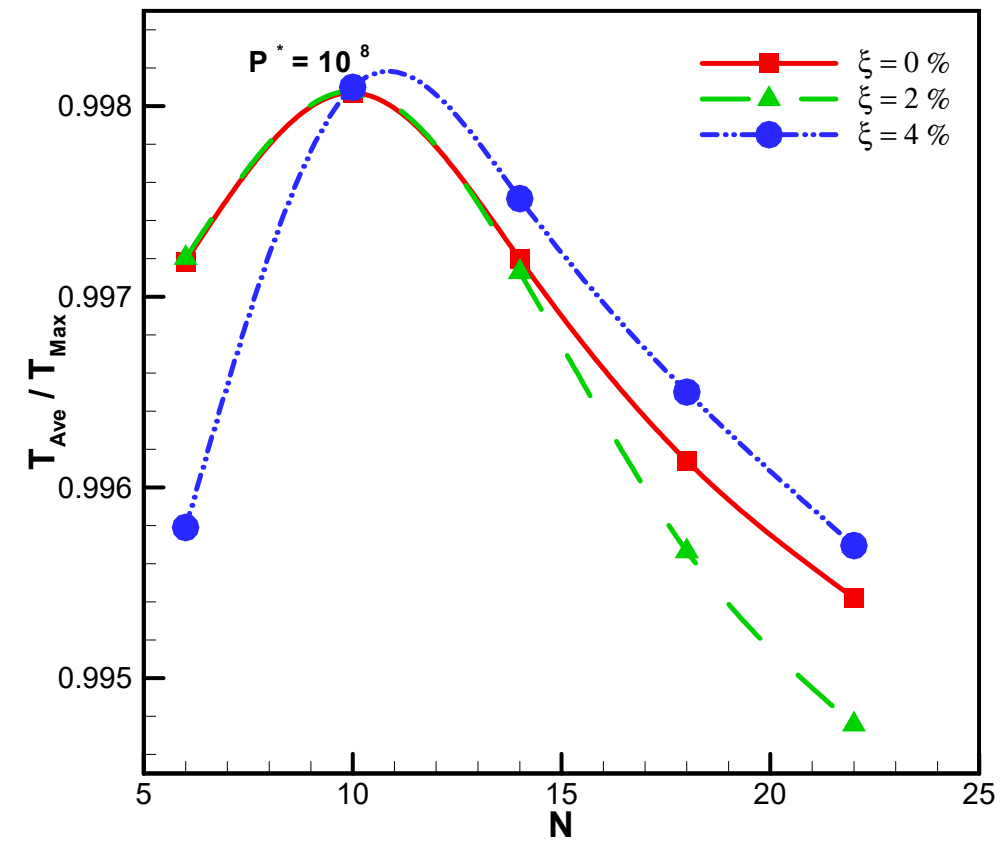

(b)

Figure 4. (a) Dimensionless average temperature versus the number of ducts at different $\xi$, under $P^{*}=10^{7}$; (b) Dimensionless average temperature versus the number of ducts at different under $\xi, P^{*}=10^{8}$.

\subsection{Mechanical Strength}

Due to the development of electronic equipment and the growing tendency of engineers to decrease the weight and dimensions of electronic segments based on industry necessities, the investigation of the mechanical strength of the electronic components is crucial. In order to examine the mechanical strength of the electronic components, mechanical parameters, such as Von Mises stress, thermal 
stresses, and the total deformation, have been investigated. Thermal expansion can be defined as the tendency of matter to change the area, shape, and volume due to a change in temperature. The resulted strains are called the temperature strains, which are not able to generate stress without a constraint; thus, they can be introduced as free strains or strains without a force. The stress, which is created by the thermal load, significantly depends on the mechanical boundary conditions.

Figure $5 \mathrm{a}, \mathrm{b}$ shows the change in peak thermal stress for various duct numbers. As observed in these figures, as a result of nanoparticle application, the peak thermal stress in the segment and the peak stress in the disks are decreased when the volume fraction of nanoparticles is increased. Whereas the peak stress in the disks increased with the duct numbers. It is noted that the slope of the stress-duct is reduced by enhancing the initial pressure and the volume fraction of nanoparticles, and eventually, the peak stress decreased. When $P^{*}{ }_{\max }=10^{7}$ and $P^{*}{ }_{\max }=10^{8}$, by increasing the volume fraction of nanoparticle from $0 \%$ to $2 \%$, the peak thermal stress varied from $13.6 \%$ to $29 \%$ and $27.6 \%$ to $42.9 \%$, respectively. Moreover, by increasing the volume fraction of nanoparticle from $0 \%$ to $4 \%$, the peak thermal stress changed from $34.3 \%$ to $51 \%$ and $38 \%$ to $54 \%$, respectively.

Figure $6 \mathrm{a}, \mathrm{b}$ depicts the peak stress originated from thermal and mechanical loading $\left(1 \times 10^{5} \mathrm{~Pa}\right)$ for various duct numbers. Figure $6 a, b$ shows that the use of nanofluid reduced the peak stress in the segment, and that the peak stress in the disks is decreased when the nanofluid volume fraction is increased. Besides, the greater the $\mathrm{N}$, the greater the peak stress. Increasing the initial pressure diminished the peak stress. The thermal loading caused equal stress at the three orients of the coordinate system. However, the mechanical loading when considering the Poisson coefficient caused stress in opposite directions. Thus, the curve showed a non-linear behavior. When $P^{*}{ }_{\max }=10^{7}$ and $P^{*}{ }_{\max }=10^{8}$, by increasing the volume fraction of nanoparticle from $0 \%$ to $2 \%$, the peak stress changed from $9.3 \%$ to $27 \%$ and $9 \%$ to $12.9 \%$, respectively. Moreover, by raising the volume fraction of nanoparticle from $0 \%$ to $4 \%$, the peak stress varied from $19 \%$ to $39 \%$ and $17 \%$ to $21 \%$, respectively.

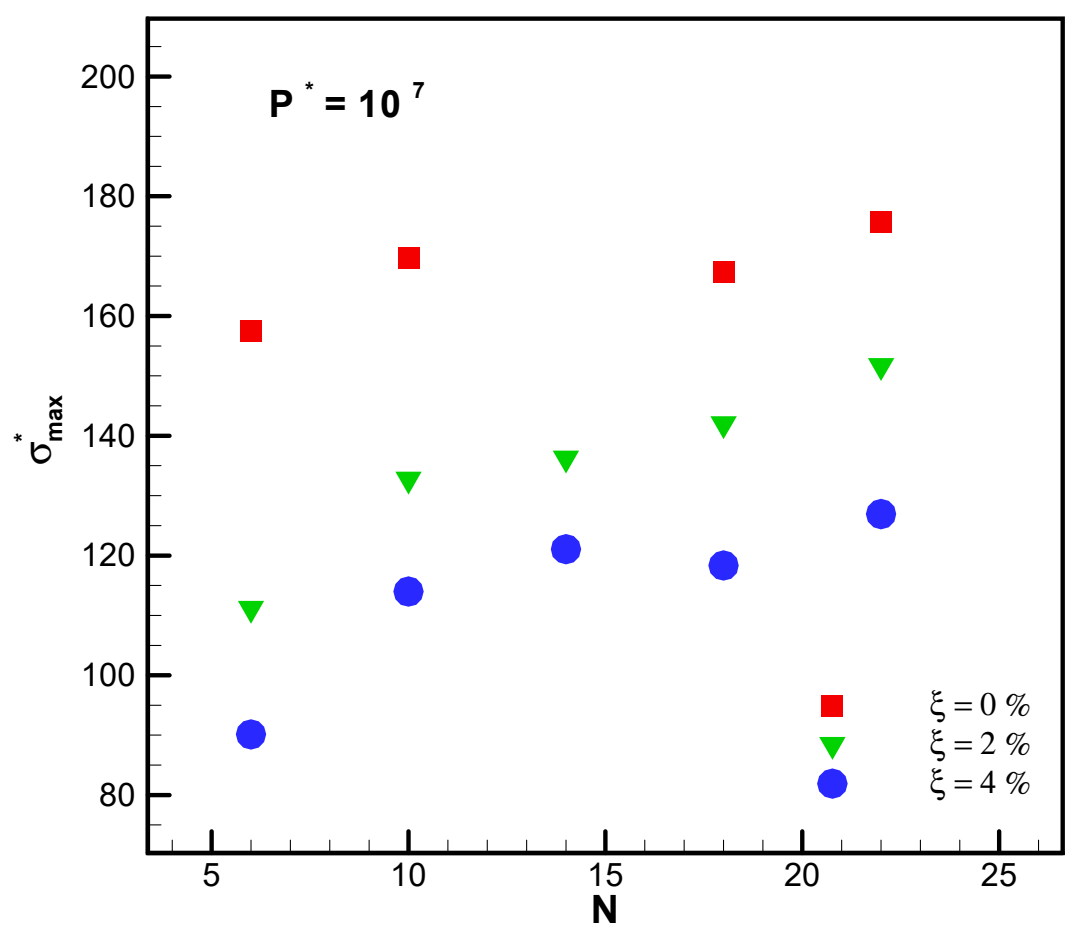

(a)

Figure 5. Cont. 


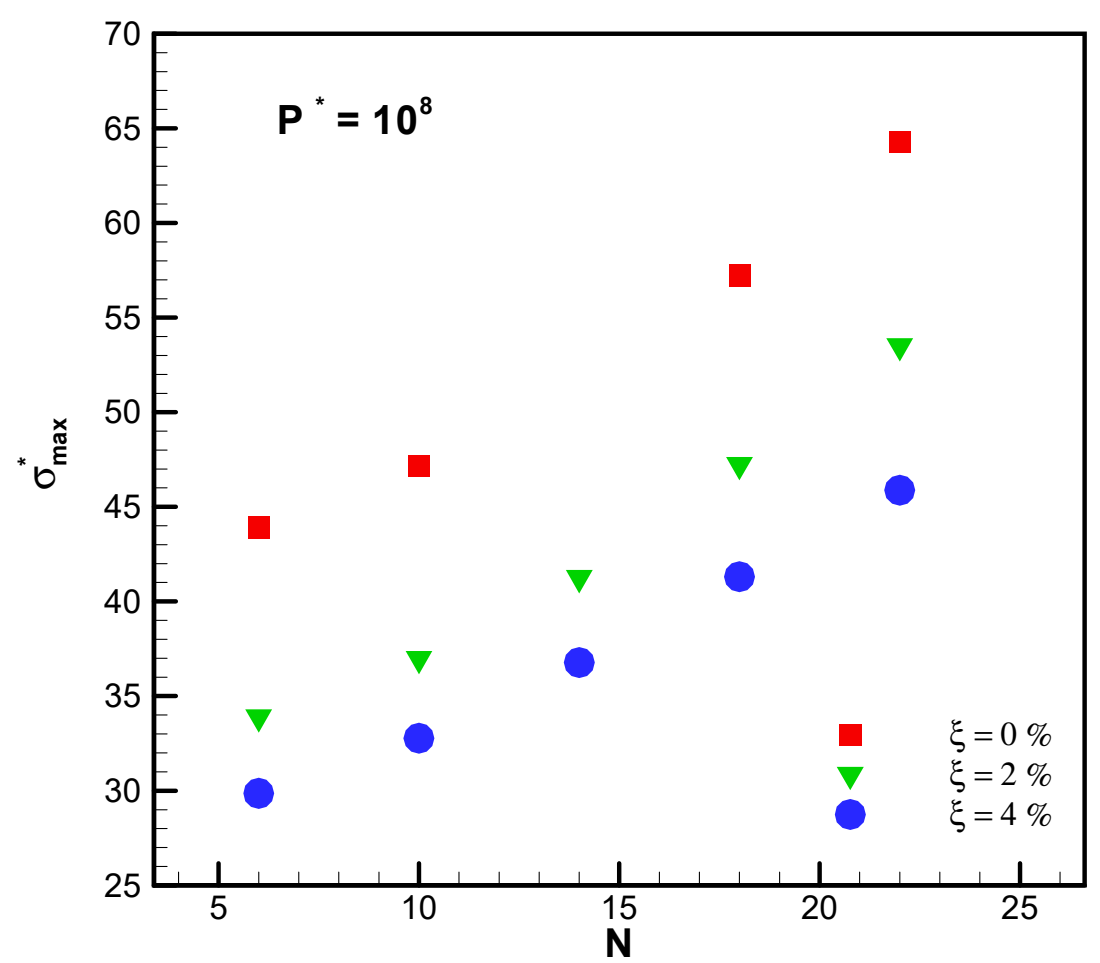

(b)

Figure 5. (a) Peak thermal stress relative to the number of cooling channels for the varying volume fraction of $\mathrm{CuO}$ Nanoparticle under $P^{*}$ max $=10^{7}$. (b) Peak thermal stress relative to the number of cooling channels for the varying volume fraction of $\mathrm{CuO}$ Nanoparticle $P^{*} \max =10^{8}$.

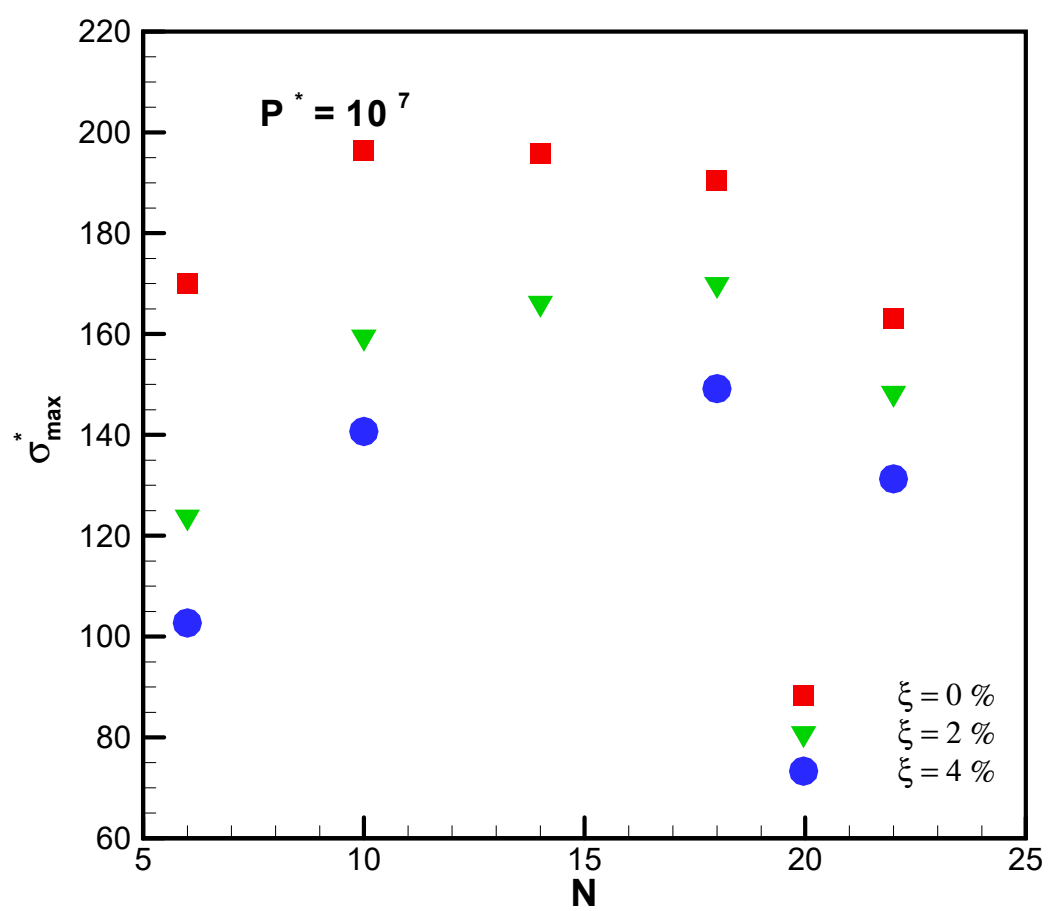

(a)

Figure 6. Cont. 


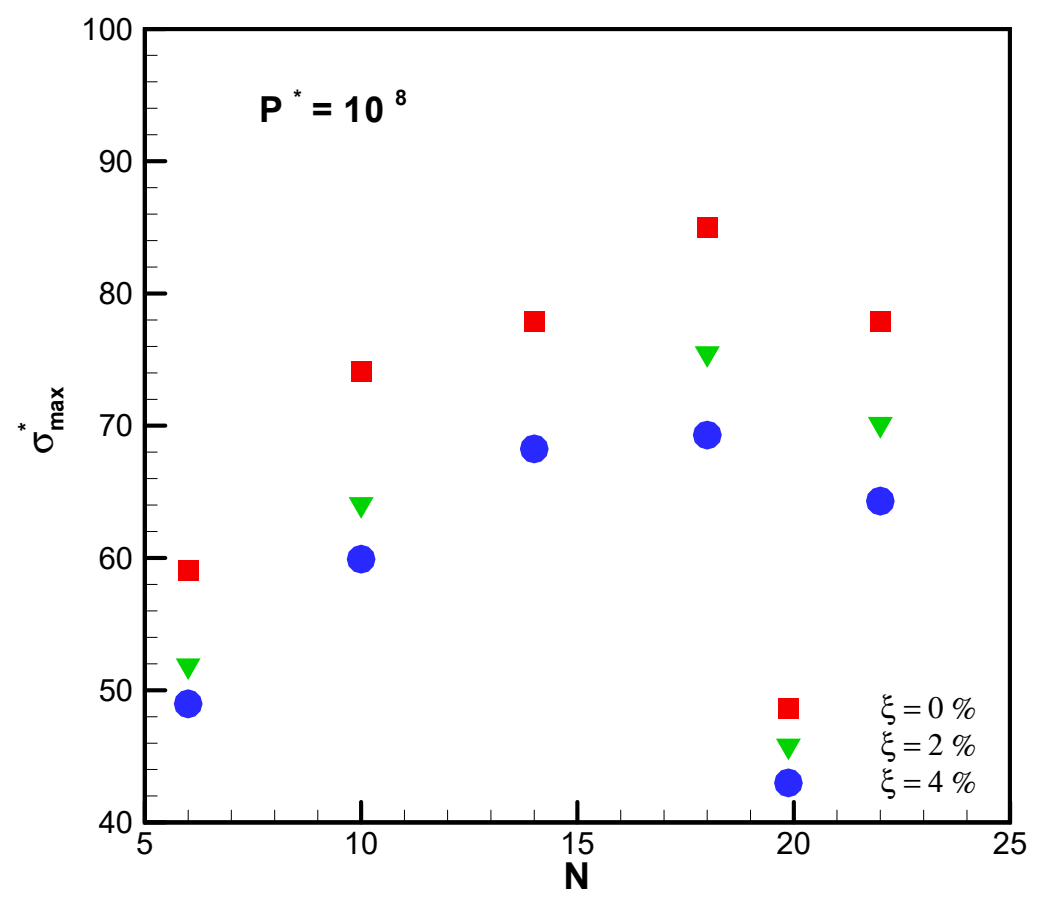

(b)

Figure 6. (a) Peak stress versus the number of cooling channels for the different volume fraction of $\mathrm{CuO}$ nanoparticle under $P^{*}=10^{7}$. (b) Peak stress versus the number of cooling channels for the different volume fraction of $\mathrm{CuO}$ nanoparticle under $P^{*}=10^{8}$.

Deformation is described as the change in the metric characteristics of a continuous body, which means that a curve drawn at the initial body placement can change its length when it is displaced to a curve at the total placement [36]. Figure 7 shows the dimensionless peak total deformation of the disk under the thermal load for different numbers of the duct.

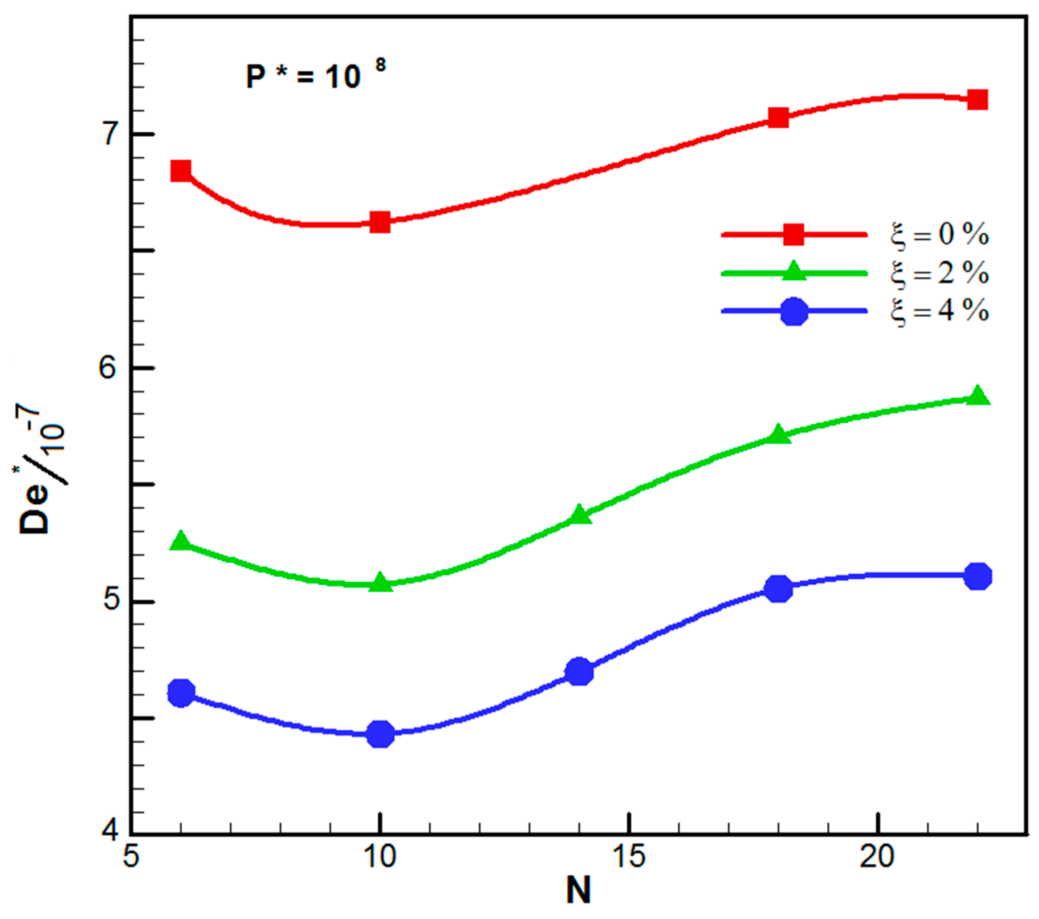

Figure 7. Dimensionless peak total deformation versus the number of cooling channels for the varying volume fraction of $\mathrm{CuO}$ nanoparticles. 
The peak deformation, which was originated from thermal loading, decreased by the increment of the nanoparticle volume fraction. At a volume fraction of $2 \%$ and $4 \%$, an average reduction of $28.3 \%$ and $35.4 \%$ was observed, respectively. Also, among the different microchannels numbers, a ten microchannel duct had the minimum peak deformation. For a number of ducts above 10, the thermal peak deformation increased with the number of microchannels.

By increasing the number of microchannels, the peak temperature, and accordingly, the peak thermal stress increased. Moreover, the mechanical loading had been diminished in comparison with the thermal loading. Therefore, as observed in Figure 8, the peak deformation is increased with the number of microchannels, but the ascribed slope is decreased. This was due to the reduction in the effect of mechanical loading compared with thermal loading. By increasing the nanoparticle volume fraction, the peak deformation is decreased. For nanoparticle concentrations of $2 \%$ and $4 \%$, between 4.3 to 17.3 and 5.7 to 23.2 percent change in the peak deformation could be observed.

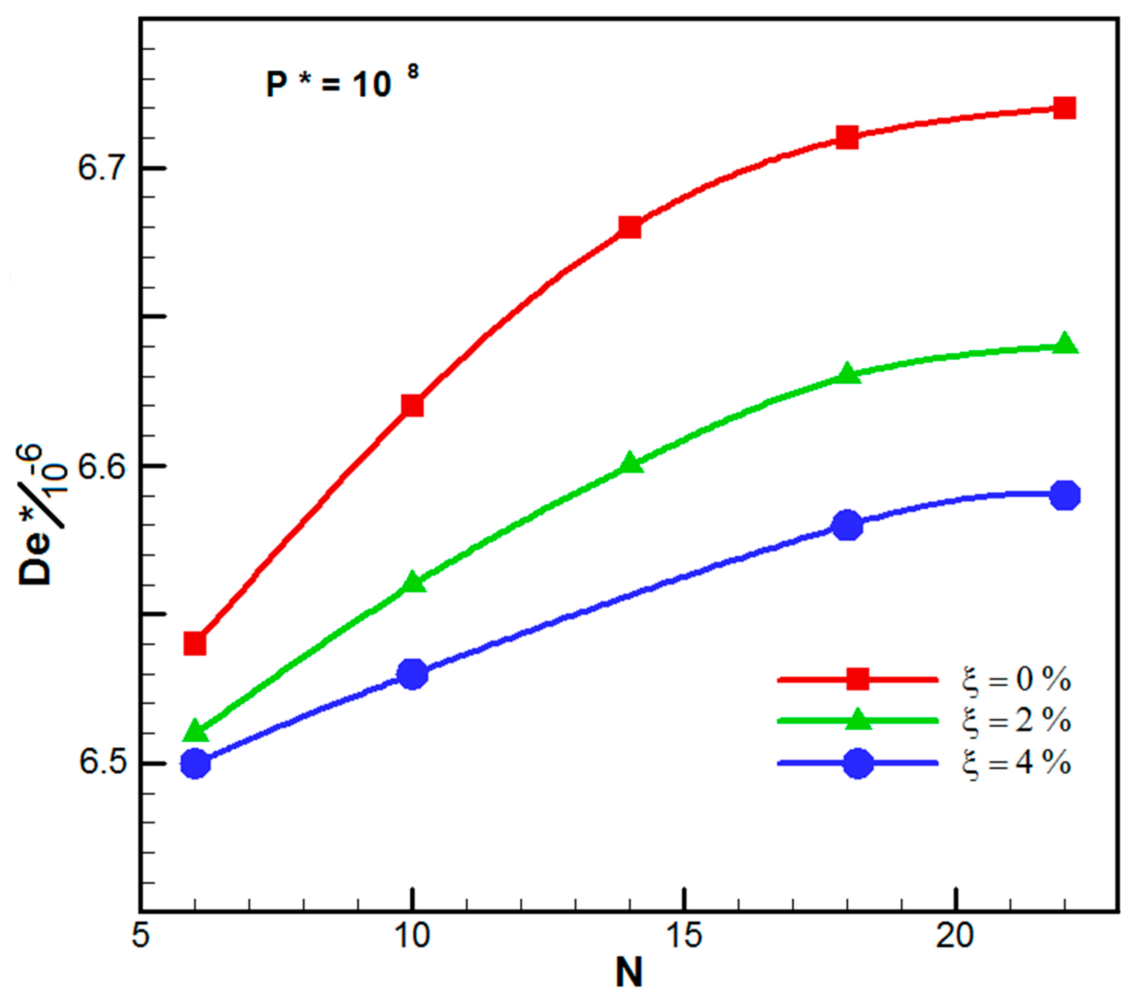

Figure 8. Dimensionless peak total deformation per $\mathrm{N}$ for various $\xi$.

In Figure 9, blue and red colors represent the maximum and minimum values, respectively. As observed in this figure, the maximum thermal strain and temperature of the disk had the same location. In addition, the minimum values are located halfway between the edge of the plate and the center. It is noted that the plate was considered a circle, concentric with the plate center. 
(a)

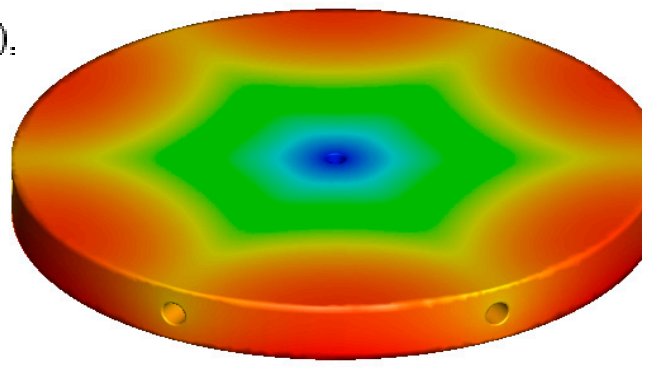

(b)

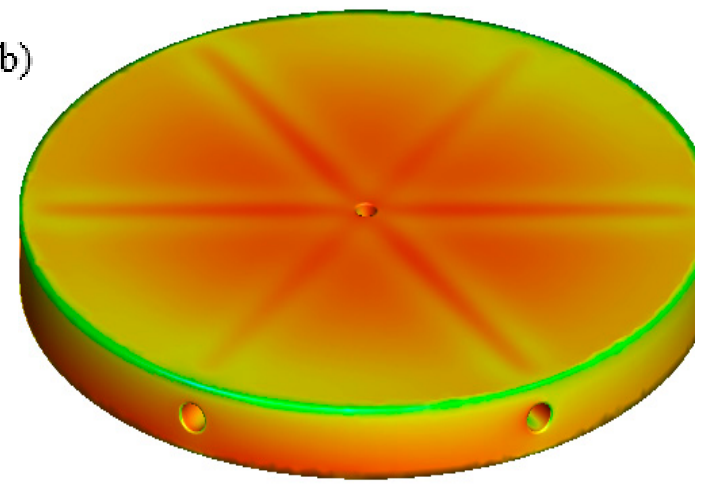

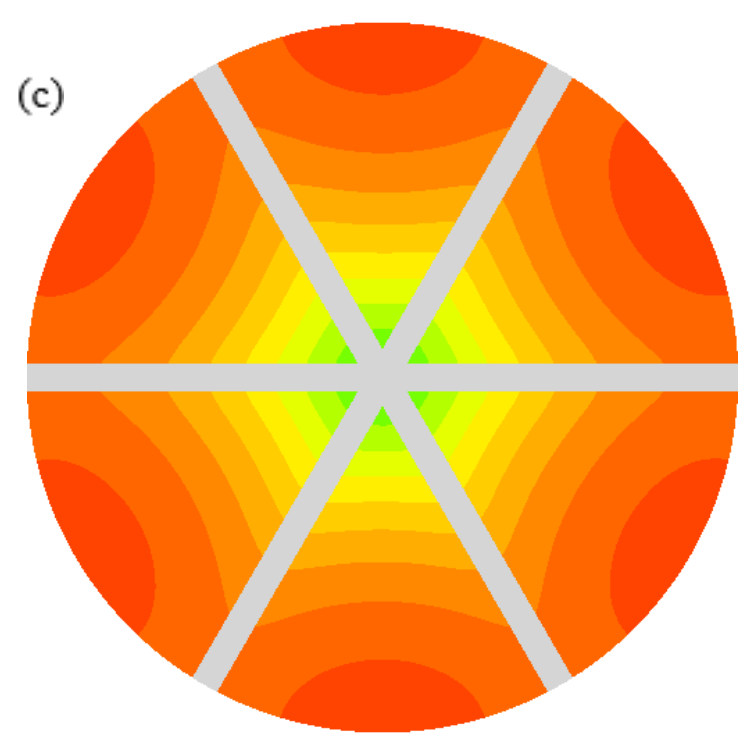

Figure 9. The contours of (a) thermal strain, (b) stress, and (c) temperature under mechanical load.

\section{Conclusions}

In this paper, the influence of using dispersed $\mathrm{CuO}$ nanoparticles in $\mathrm{H}_{2} \mathrm{O}$ flowing through a network of radial microchannels from the mechanical and thermal points of view was investigated. In all studied cases, the fluid volume of the cooling zone was assumed to be constant in the solid region, and the effect of using nanofluid in concentrations of 2 and 4 percent was investigated. The results indicated that $\mathrm{CuO}$ nanoparticles reduced the average of the maximum disk temperature, the maximum thermal stress, and the maximum stress, as well as the most significant deformation in the studied configuration. Increasing the number of microchannels would increase the maximum stress in the object, as well. Another remarkable point was that increasing the nanoparticles did not necessarily lead to a more uniform heat distribution in the disk.

Author Contributions: All authors (R.D., G.A.S., M.R.S., A.S.L., and M.G.) have contributed equally. All authors have read and agreed to the published version of the manuscript.

Funding: This research received no external funding.

Conflicts of Interest: The authors declare no conflict of interest.

\section{Nomenclature}

\section{Nomenclature}

$C_{p}$

$D$

De

H
Specific heat capacity $\left(\mathrm{J} \mathrm{kg}^{-1} \mathrm{~K}^{-1}\right)$

The thickness of the microchannel (m)

Deformation (m)

The height of the disk (m) 


\begin{tabular}{ll}
$L$ & Length $(\mathrm{m})$ \\
$M$ & Mass flow rate $\left(\mathrm{kg} \mathrm{s}^{-1}\right)$ \\
$N$ & Number of branching \\
$P$ & Pressure $\left(\mathrm{N} \mathrm{m}^{-2}\right)$ \\
$P r$ & Prandtl number \\
$q^{\prime \prime}$ & Heat flux $\left(\mathrm{W} \mathrm{m}^{-2}\right)$ \\
$T$ & Temperature $(\mathrm{K})$ \\
$u, v, w$ & Velocity components $\left(\mathrm{m} \mathrm{s}^{-1}\right)$ \\
Greek symbols & \\
$A$ & Thermal expansion coefficient $\left(\mathrm{K}^{-1}\right)$ \\
$\gamma$ & Poisson's ratio \\
$\sigma$ & Normal stress $(\mathrm{Pa})$ \\
$\mu$ & Dynamic viscosity $\left(\mathrm{kg} \mathrm{m}^{-1} \mathrm{~s}^{-1}\right)$ \\
$\tau$ & Shear stress $(\mathrm{Pa})$ \\
$\xi$ & The volume fraction of nanoparticles \\
$\rho$ & Density $\left(\mathrm{kg} \mathrm{m}^{-3}\right)$ \\
$\varphi$ & Shear strain $\left(\mathrm{mm} \mathrm{mm} \mathrm{mm}^{-1}\right)$ \\
Subscripts & \\
ave & \\
$b f$ & Average \\
$n f$ & Base Fluid \\
$s$ & Nano fluid \\
$r e f$ & Solid \\
Superscripts & Reference \\
$\left.{ }^{*}\right)$ & \\
\hline & Dimensionless
\end{tabular}

\section{References}

1. Bahiraei, M.; Salmi,H.K.; Safaei, M.R. Effect of employing a new biological nanofluid containing functionalized graphene nanoplatelets on thermal and hydraulic characteristics of a spiral heat exchanger. Energy Convers. Manag. 2019, 180, 72-82. [CrossRef]

2. Farzaneh, M.; Salimpour, M.R.; Tavakoli, M.R. Design of bifurcating microchannels with/without loops for cooling of square-shaped electronic components. Appl. Therm. Eng. 2016, 108, 581-595. [CrossRef]

3. Ghaedamini, H.; Salimpour, M.; Campo, A. Constructal design of reverting microchannels for convective cooling of a circular disc. Int. J. Therm. Sci. 2011, 50, 1051-1061. [CrossRef]

4. Haghighi, S.S.; Goshayeshi, H.; Safaei, M.R. Natural convection heat transfer enhancement in new designs of plate-fin based heat sinks. Int. J. Heat Mass Transf. 2018, 125, 640-647. [CrossRef]

5. Al-Rashed, A.A.A.; Hassen, W.; Kolsi, L.; Oztop, H.F.; Chamkha, A.J.; Abu-Hamdeh, N. Three-dimensional analysis of natural convection in nanofluid-filled parallelogrammic enclosure opened from top and heated with square heater. J. Cent. South Univ. 2019, 26, 1077-1088. [CrossRef]

6. Dogonchi, A.; Chamkha, A.J.; Hashemi-Tilehnoee, M.; Seyyedi, S.; Ganji, D. Effects of homogeneousheterogeneous reactions and thermal radiation on magneto-hydrodynamic $\mathrm{Cu}$-water nanofluid flow over an expanding flat plate with non-uniform heat source. J. Cent. South Univ. 2019, 26, 1161-1171. [CrossRef]

7. Dogonchi, A.S.; Chamkha, A.J.; Seyyedi, S.M.; Hashemi-Tilehnoee, M.; Ganji, D.D. Viscous Dissipation Impact on Free Convection Flow of Cu-water Nanofluid in a Circular Enclosure with Porosity Considering Internal Heat Source. J. Appl. Comput. Mech. 2019, 5, 717-726.

8. Alkasassbeh, M.; Omar, Z.; Mebarek-Oudina, F.; Raza, J.; Chamkha, A. Heat transfer study of convective fin with temperature-dependent internal heat generation by hybrid block method. Heat Transf.-Asian Res. 2019, 48, 1225-1244. [CrossRef]

9. Kumar, P.S.; Gireesha, B.; Mahanthesh, B.; Chamkha, A.J. Thermal analysis of nanofluid flow containing gyrotactic microorganisms in bioconvection and second-order slip with convective condition. J. Therm. Anal. Calorim. 2019, 136, 1947-1957. [CrossRef]

10. Izadi, M.; Pour, S.H.; Yasuri, A.K.; Chamkha, A.J. Mixed convection of a nanofluid in a three-dimensional channel. J. Therm. Anal. Calorim. 2019, 136, 2461-2475. [CrossRef] 
11. Ghalambaz, M.; Tahmasebi, A.; Chamkha, A.; Wen, D. Conjugate local thermal non-equilibrium heat transfer in a cavity filled with a porous medium: Analysis of the element location. Int. J. Heat Mass Transf. 2019, 138, 941-960. [CrossRef]

12. Bahiraei, M.; Jamshidmofid, M.; Goodarzi, M. Efficacy of a hybrid nanofluid in a new microchannel heat sink equipped with both secondary channels and ribs. J. Mol. Liq. 2019, 273, 88-98. [CrossRef]

13. Dadsetani, R.; Sheikhzadeh, G.A.; Hajmohammadi, M.R.; Safaei, M.R. Introduce a novel configuration of microchannel andhigh-conductivity insertsfor cooling of disc-shaped electronic components. Int. J. Numer. Methods Heat Fluid Flow 2019. [CrossRef]

14. Dadsetani, R.; Salimpour, M.R.; Tavakoli, M.R.; Goodarzi, M.; Bandarra Filho, E.P. Thermal and Mechanical Design of Reverting Microchannels for Cooling Disk-Shaped Electronic Parts Using Constructal Theory. Available online: https://doi.org/10.1108/HFF-06-2019-0453 (accessed on 20 March 2020).

15. Tuckerman, D.B.; Pease, R.F.W. High-performance heat sinking for VLSI. IEEE Electron Device Lett. 1981, 2, 126-129. [CrossRef]

16. Bejan, A. Street network theory of organization in nature. J. Adv. Transp. 1996, 30, 85-107. [CrossRef]

17. Chol, S.; Estman, J. Enhancing thermal conductivity of fluids with nanoparticles. Asme-Publ.-Fed 1995, 231, 99-106.

18. Dadsetani, R.; Sheikhzadeh, G.A.; Safaei, M.R.; Alnaqi, A.A.; Amiriyoon, A. Exergoeconomic optimization of liquefying cycle for noble gas argon. Heat Mass Transf. 2018, 55, 1995-2007. [CrossRef]

19. Selimefendigil, F.; Chamkha, A.J. Magnetohydrodynamics mixed convection in a lid-driven cavity having a corrugated bottom wall and filled with a non-Newtonian power-law fluid under the influence of an inclined magnetic field. J. Therm. Sci. Eng. Appl. 2016, 8, 021023. [CrossRef]

20. Selimefendigil, F.; Öztop, H.F. Effects of nanoparticle shape on slot-jet impingement cooling of a corrugated surface with nanofluids. J. Therm. Sci. Eng. Appl. 2017, 9, 021016. [CrossRef]

21. Sheikhzadeh, G.; Dastmalchi, M.; Khorasanizadeh, H. Effects of walls temperature variation on double diffusive natural convection of $\mathrm{Al}_{2} \mathrm{O}_{3}$-water nanofluid in an enclosure. Heat Mass Transf. 2013, 49, 1689-1700. [CrossRef]

22. Sheikhzadeh, G.; Nikfar, M. Aspect ratio effects of an adiabatic rectangular obstacle on natural convection and entropy generation of a nanofluid in an enclosure. J. Mech. Sci. Technol. 2013, 27, 3495-3504. [CrossRef]

23. Teimouri, H.; Sheikhzadeh, G.A.; Afrand, M.; Fakhari, M.M. Mixed convection in a rotating eccentric annulus containing nanofluid using bi-orthogonal grid types: A finite volume simulation. J. Mol. Liq. 2017, 227, 114-126. [CrossRef]

24. Bagherzadeh, S.A.; D'Orazio, A.; Karimipour, A.; Goodarzi, M.; Bach, Q.-V. A novel sensitivity analysis model of EANN for F-MWCNTs- $\mathrm{Fe}_{3} \mathrm{O}_{4} / \mathrm{EG}$ nanofluid thermal conductivity: Outputs predicted analytically instead of numerically to more accuracy and less costs. Phys. A Stat. Mech. Its Appl. 2019, 521, 406-415. [CrossRef]

25. Afridi, M.I.; Tlili, I.; Goodarzi, M.; Osman, M.; Khan, N.A. Irreversibility Analysis of Hybrid Nanofluid Flow over a Thin Needle with Effects of Energy Dissipation. Symmetry 2019, 11, 663. [CrossRef]

26. Nazari, M.A.; Ahmadi, M.H.; Sadeghzadeh, M.; Shafii, M.B.; Goodarzi, M. A review on application of nanofluid in various types of heat pipes. J. Cent. South Univ. 2019, 26, 1021-1041. [CrossRef]

27. Jiang, Y.; Bahrami, M.; Bagherzadeh, S.A.; Abdollahi, A.; Sulgani, M.T.; Karimipour, A.; Goodarzi, M.; Bach, Q.-V. Propose a new approach of fuzzy lookup table method to predict $\mathrm{Al}_{2} \mathrm{O}_{3}$ /deionized water nanofluid thermal conductivity based on achieved empirical data. Phys. A Stat. Mech. Its Appl. 2019, 527, 121177. [CrossRef]

28. Nikkhah, Z.; Karimipour, A.; Safaei, M.R.; Forghani-Tehrani, P.; Goodarzi, M.; Dahari, M.; Wongwises, S. Forced convective heat transfer of water/functionalized multi-walled carbon nanotube nanofluids in a microchannel with oscillating heat flux and slip boundary condition. Int. Commun. Heat Mass Transf. 2015, 68, 69-77. [CrossRef]

29. Safaei, M.R.; Gooarzi, M.; Akbari, O.A.; Shadloo, M.S.; Dahari, M. Performance evaluation of nanofluids in an inclined ribbed microchannel for electronic cooling applications. In Electronics Cooling; IntechOpen: Zagreb, Croatia, 2016.

30. Akbari, O.A.; Toghraie, D.; Karimipour, A.; Safaei, M.R.; Goodarzi, M.; Alipour, H.; Dahari, M. Investigation of rib's height effect on heat transfer and flow parameters of laminar water- $\mathrm{Al}_{2} \mathrm{O}_{3}$ nanofluid in a rib-microchannel. Appl. Math. Comput. 2016, 290, 135-153. 
31. Nojoomizadeh, M.; D’Orazio, A.; Karimipour, A.; Afrand, M.; Goodarzi, M. Investigation of permeability effect on slip velocity and temperature jump boundary conditions for FMWNT/Water nanofluid flow and heat transfer inside a microchannel filled by a porous media. Phys. E Low-Dimens. Syst. Nanostruct. 2018, 97, 226-238. [CrossRef]

32. Menni, Y.; Azzi, A.; Chamkha, A. Enhancement of convective heat transfer in smooth air channels with wall-mounted obstacles in the flow path. J. Therm. Anal. Calorim. 2019, 135, 1951-1976. [CrossRef]

33. Cetkin, E.; Lorente, S.; Bejan, A. Vascularization for cooling and mechanical strength. Int. J. Heat Mass Transf. 2011, 54, 2774-2781. [CrossRef]

34. Gosselin, L.; Bejan, A. Constructal heat trees at micro and nanoscales. J. Appl. Phys. 2004, 96, 5852-5859. [CrossRef]

35. Çetkin, E.; Lorente, S.; Bejan, A. Vascularization for cooling and reduced thermal stresses. Int. J. Heat Mass Transf. 2015, 80, 858-864. [CrossRef]

36. Lubliner, J. Plasticity Theory; Courier Corporation: New York, NY, USA, 2008.

(C) 2020 by the authors. Licensee MDPI, Basel, Switzerland. This article is an open access article distributed under the terms and conditions of the Creative Commons Attribution (CC BY) license (http://creativecommons.org/licenses/by/4.0/). 